DOI: http://doi.org/10.4038/jrrisl.v100i0.1896

Journal of the Rubber Research Institute of Sri Lanka (2020) 100, 1-21

\title{
Effect of tapping rest during wintering months on latex yield and tapping panel dryness in three rubber (Hevea brasiliensis) clones
}

\author{
P Seneviratne*, N M C Nayanakantha*, R K Samarasekara* and \\ W K S W Watawala*
}

* Rubber Research Institute of Sri Lanka, Dartonfield, Agalawatta, Sri Lanka

\begin{abstract}
Hevea brasiliensis (Muell Arg.) undergoes annual leaf shedding commonly known as wintering. The wintering period in the traditional rubber growing areas in the Wet Zone of Sri Lanka is from December to February followed by flowering and flushing in March. Tapping rest during wintering is recommended in certain countries while in some other countries year round tapping is practiced. In Sri Lanka, until early1970s winter resting was practiced, but this is not being practiced at present. Incidence of tapping panel dryness appears to be high with currently recommended clones and hence the objective of the present study was to investigate on the effect of winter resting on the annual yield and tapping panel dryness in rubber clones. Experimental trials were conducted for two consecutive years (2018 and 2019) with three clones viz., RRIC 100, RRIC 121 and RRISL 203 at the Substation of RRISL at Kuruwita in Ratnapura district. Treatments tested were continued tapping with no winter rest (T1), resting during the wintering period (T2) and once in six days tapping during the wintering period (T3). Trees were tapped at S/2d3(once in three days) intensity. Data were collected on latex volume, bark consumption and TPD incidences. Results for two years showed higher $g / t / t /$ in all three clones when rested during the wintering period in both years as compared to those with no winter rest. Significantly higher annual total crop ( $\mathrm{kg}$ ) was recorded for $T 1$ when compared to $T 2$ in all three clones for both years. Though total number of partially and totally dry trees of winter rested trees of clones RRIC 100 and RRIC 121 were low, the differences were not significant. In terms of profits obtained as indicated by economic analysis, resting the trees during wintering resulted in the highest profits, followed by d6 tapping during the same period. Winter rest should be tested for a longer duration (4-5 years) for all the clones recommended at present that are vulnerable to tapping panel dryness.
\end{abstract}

Key words: bark consumption, Hevea, rubber, tapping panel dryness, winter rest, yield

\section{Introduction}

Wintering is a term that is used to describe the annual shedding of senescent leaves which renders the tree partially or fully leafless for a period of time. Unlike in trees in temperate countries where defoliation occurs during the winter period of the year, in 
rubber which grows in tropical countries, wintering takes place during the drier months of the year. Rubber trees, generally of more than four to five years of age, undergo this phenomenon for about two to three months, from December to February in traditionally rubber grown areas (Nayanakantha and Seneviratne, 2008), wintering is followed by the terminal bud bursting and expansion of new leaves. Yield reduction has been recorded during this period due to reduction of sucrose content in cells which is aggravated during re-foliation followed by flowering; all demands extra resources Priyadarshan, (2011).

The physiology behind senescence and abscission of leaves is identified as an imbalance between growth promoter Indole Acetic Acid (IAA) and growth inhibitor Abscisic Acid (AA). According to Priyadarshan, (2011), defoliation of rubber is a circumvent process to overcome moisture and low temperature stress through minimizing transpiration and to ensure reproduction. The tree, acquiring new leaves without undue damage by diseases such as Oidium and Colletotrichum, by this process, is considered to have an added advantage. Temperature and rainfall are two major factors that influence on yield and phenology of rubber. As reported by George et al., (1980) and Meenattoor et al. (1989) wintering depends on the clone, age of the plants, location and agro climatic conditions and the weather prevailing. It has been evidenced that the duration of wintering tends to be short in areas experiencing a dry period. Refoliation is completed fast minimizing yield reduction in such areas. All the leaves fall within a short period of time followed by a rapid re-foliation under that situation. On the other extreme, where there is no pronounced dry season with infrequent low rainfall leaf fall occurs gradually. Reduction of yield is greater under this condition.

In Sri Lanka research have been done to study the pattern of wintering with the clones available by Pathologists to understand about disease spread, severity and also to plan or to decide on chemical spraying to control diseases. As reported by Liyanage (1976), wintering has been induced by drier weather and much influenced by rainfall occurring during the period as observed in clone PB 86, in an experiment conducted in almost all rubber growing areas in Sri Lanka. Weather pattern has been reported as the closest factor to influence on the pattern and the time of wintering. Age of the trees seems to influence the pattern of wintering; the older trees seem to defoliate and re-foliate earlier than younger trees. The pattern of wintering has been observed of clones RRIC 7, RRIC 45, RRIC 52 and PB 86 by Wimalaratne and Pathiratne (1974) and indicated that resting was not necessary until the bud break starts where the yield drop is not up to uneconomical level. However, only two weeks rest has been recommended for the local clones and even a shorter period for PB 86 .

Nayanakantha and Seneviratne (2008) conducted studies on wintering and flowering patterns of eighteen Hevea clones in Wet and Intermediate Zones of Sri Lanka. Significant early wintering was observed in clones of RRISL 223, 
P Seneviratne et al.

RRIC 100, and RRISL 216 in Dartonfield while in Kuruwita, RRISL 217, RRIC 100, RRISL 201 and RRISL 202 clones showed early wintering. It was also found that there was no significant difference in wintering and flowering patterns of RRIC 100 between Pitiyakande which located in Intermediate Zone and most of the sites in wet zone and the same pattern was observed with RRIC 121 (Nayanakantha and Seneviratne, 2008).

Tapping rest during wintering period is recommended in some countries (Martin, 1969 and Chantuma, et al., 2017) while in some other countries year round tapping is practiced Meenattoor (1989). Earlier it was a common practice to stop tapping during wintering (winter rest) in Sri Lanka. Majority of the small holders practiced this while estate sector did not adopt it mainly due to high rubber prices during this period. Currently winter resting is not recommended by RRISL and not practiced in any of the sectors. As per the records available, until 1970s winter resting was recommended in Sri Lanka, but after that RRISL had recommended to tap during the wintering period too, based on the results of an experiment carried out for a nine year period, from 1964 to 1972, with clones PB 86 and NAB 12 (Annual Review, 1972). The main treatment had been with and without winter rest, but stimulations and different tapping frequencies had also been tested over the period. After nine years it had been concluded that no significant difference in the yield whether the trees were winter rested or not. PB 86 then has been considered a high yielding clone and during the last of the trial the yield had been around $37 \mathrm{~g} / \mathrm{t} / \mathrm{t}$ on $\mathrm{S} 2 \mathrm{~d} 2$ tapping when the trees were 20 years of age with average girth of about $70 \mathrm{~cm}$.

Over the past decades, the potential rubber yield has been significantly increased, due to the cultivation of high yielding clones and adopting improved agro-management practices. However, latex production still faces serious economic losses caused by high percentage of tapping panel dryness (TPD). Annual rubber production loss due to TPD accounted for $15-20 \%$ (Chen et al., 2002) and no effective treatments has been developed for it so far (Li et al., 2010). In the current context, high tapping panel dryness incidences are being reported, especially of the clones recommended after 1990s. It is hypothesized that the tapping frequency of $\mathrm{d} 2$ or $\mathrm{d} 3$ with ethrel may be too harsh for the high yielding clones and also, continuous tapping without a rest during wintering and flowering period could be one of the major reasons for trees to become stressed and occurrence of high TPD in rubber clones.

The current study, was thus, aimed at investigating the effect of tapping rest during the wintering and flowering period on latex yield and tapping panel dryness incidence in three selected rubber clones.

\section{Materials and Methods Location and duration}

Experimental trials were conducted at the Substation of RRISL at Kuruwita in Ratnapura district belonging to WL2 Agro-climatic Zone, for two consecutive years, 2018 and 2019. 
Plant materials, treatments and design

Three fields representing three clones viz., RRIC 100, RRIC 121 and RRISL 203 were selected for the present study. The year of planting of the three clones were 1993, 2005 and 2009 respectively. Ninety trees were selected from each experimental field avoiding runts and tapping panel dried trees. There were three blocks for each experimental field and each block had ten trees per treatment distributed randomly so that each treatment was imposed for 30 trees (replicates). Treatments tested were as follows.

T1- continues tapping with no winter rest

T2- resting or no tapping during the wintering period

T3- tapping at d6 frequency during the wintering period

Trees were tapped at $\mathrm{S} / 2 \mathrm{~d} 3$ intensity, as practiced on the estate. As the trees of above mentioned clones should be tapped at $\mathrm{S} / 2 \mathrm{~d} 2$ frequency as per the recommendation of RRISL, trees were stimulated using $2.5 \%$ ethrel in order to tap at $\mathrm{S} / 2 \mathrm{~d} 3$ frequency. Although four rounds of ethereal application was planned, only two rounds could be applied as panel application for all clones. In 2018, application dates were $21^{\text {st }}$ August and $21^{\text {st }}$ December and in 2019 they were $16^{\text {th }}$ May and $1^{\text {st }}$ August. Tapping was stopped for the winter resting treatment when the leaves started to fall and recommenced when majority of the leaves turned in to apple green color. Winter resting period for 2018 and 2019 were from 29.01.2018 to
02.05.2018 and 27.01.2019 to 03.04.2019 respectively.

\section{Data collection and analysis}

Total volume for ten trees per block i.e. each treatment, was measured and recorded on every tapped day. Metrolac reading was taken for the treatment bulk. Bark consumption was calculated using the difference between the starting and the finishing panel height for each year. The percentage of incidence of tapping panel dryness (\%TPD) was calculated for each treatment using following formula. Three clones were tapped by three tappers.

$\% \mathrm{TPD}=(\mathrm{TPD}$ tress/Total trees $) \times 100$

Bark consumption was measured using a tape and the girth was measured at $60 \mathrm{~cm}$ from the bud union using a tape. Partial and total tapping panel dryness condition was assessed when trees being tapped.

Significance of the observed treatment differences was tested by analysis of variance using proc ANOVA procedure of the SAS software package (version 9.1) and significant means were separated using the least significant difference (LSD).

Financial analysis was conducted to measure the economic viability of implementing the treatments in the three clones. Hence cost and income per one hectare of rubber land was calculated separately for the three treatments. Tapping cost was based on the current daily wage of workers LKR 1000 and Ethrel application cost. Selling price of one kilogram of rubber was considered as LKR 300. Stand per hectare is 
P Seneviratne et al.

considered as 500 trees and number of trees for a tapping block as 250 trees. Wintering periods were three months and two months for 2018 and 2019 respectively.

\section{Results}

Monthly total crop of the ten trees for the two years and for three treatments, for continuous tapping (T1), winter rested (T2) and d6 tapping during the wintering period (T3) for the three clones are given in Tables 1a (for RRIC 100), 1b (for RRIC 121) and 1c (for RRISL 203). The behavior of crop pattern is similar for all three clones. Total monthly crop is higher, especially during cropping months, when trees were rested during wintering period. But, the annual total crop is lower when the trees were winter rested, due to lower number of tapping days when rested during wintering period.

The impact of the duration of wintering period on the monthly crop is clear from the data for all three clones. The trees under continuous tapping have resumed the high crop, as per the general crop pattern only in July for all three treatments in 2018 where the wintering period was three months. But in 2019, wintering period was only for two months and the high crop is resumed in May-June, i.e., 1-2 months earlier than 2018.

Table 1a. The monthly total crop $(\mathrm{kg})$ of ten trees for the three treatments, for continuous tapping (T1), winter rested (T2) and d6 tapping during the wintering period (T3) of the clone RRIC 100 for the two years

\begin{tabular}{|c|c|c|c|c|c|c|c|c|c|c|c|c|c|}
\hline \multirow{3}{*}{ } & \multicolumn{12}{|c|}{2018} & \multirow{3}{*}{ 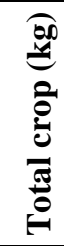 } \\
\hline & \multicolumn{12}{|c|}{ Total crop $(\mathbf{k g})$} & \\
\hline & $\stackrel{\Xi}{\Xi}$ & 8 & $\dot{\Xi}$ & $\frac{\grave{c}}{4}$ & $\sum^{\mathrm{E}}$ & $\Xi$ & $\Xi$ & $\frac{600}{Z}$ & ఫे & $\bar{\delta}$ & z & $\stackrel{\mathscr{\Xi}}{0}$ & \\
\hline T1 & 5.9 & 1.1 & 3.1 & 2.7 & 2.4 & 2.7 & 10.4 & 9.9 & 10.1 & 10.1 & 7.7 & 12.9 & 79 \\
\hline T2 & 6.0 & & & & 2.3 & 2.5 & 11.0 & 10.4 & 11.7 & 9.4 & 7.7 & 12.6 & 73 \\
\hline T3 & 5.9 & 0.4 & 0.7 & 0.9 & 2.3 & 2.6 & 10.2 & 9.9 & 10.4 & 9.5 & 7.5 & 12.7 & 73 \\
\hline & \multicolumn{12}{|c|}{2019} & \\
\hline T1 & 15.9 & 7.1 & 5.9 & 1.9 & 6.8 & 14.2 & 12.8 & 2.5 & 3.2 & 2.3 & 3.3 & 2.9 & 79 \\
\hline T2 & 17.2 & & & & 6.9 & 13.5 & 12.9 & 2.6 & 3.2 & 2.2 & 3.5 & 2.9 & 66 \\
\hline T3 & 16.5 & 3.7 & 3.8 & 1.8 & 6.3 & 13.3 & 12.3 & 2.6 & 3.0 & 2.2 & 3.3 & 2.9 & 72 \\
\hline
\end{tabular}


Effect of winter resting on yield

Table 1b. The monthly total crop ( $\mathrm{kg}$ ) of ten trees for the three treatments, continuous tapping (T1), winter rested (T2) and d6 tapping during the wintering period (T3) of the clone RRIC 121 for the two years

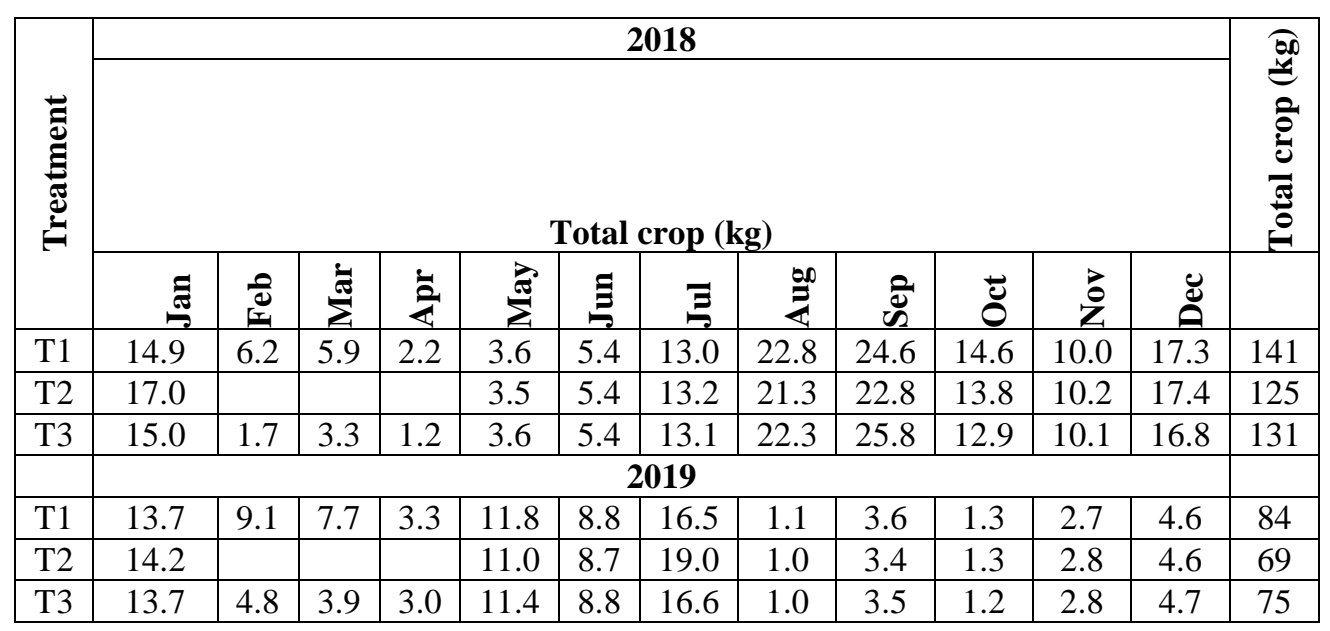

Table 1c. The monthly total crop $(\mathrm{kg})$ of ten trees for the three treatments, continuous tapping (T1), winter rested (T2) and d6 tapping during the wintering period (T3) of the clone RRISL203 for the two years

\begin{tabular}{|c|c|c|c|c|c|c|c|c|c|c|c|c|c|}
\hline \multirow{3}{*}{ 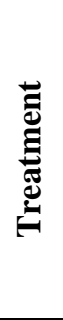 } & \multicolumn{12}{|c|}{2018} & \multirow{3}{*}{ 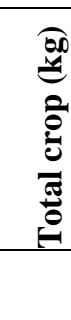 } \\
\hline & \multicolumn{12}{|c|}{ Total crop (kg) } & \\
\hline & $\tilde{\Xi}$ & \& & $\dot{\bar{\pi}}$ & $\dot{\vec{k}}$ & $\vec{j}$ & $\Xi$ & $\Xi$ & $\stackrel{900}{Z}$ & चे & $\overrightarrow{\mathrm{e}}$ & $\vec{z}$ & $\ddot{\mathscr{U}}$ & \\
\hline T1 & 9.7 & 1.5 & 3.8 & 2.9 & 2.3 & 2.9 & 10.9 & 10.4 & 9.9 & 9.2 & 10.4 & 16.2 & 90 \\
\hline $\mathrm{T} 2$ & 9.6 & & & & 2.3 & 2.9 & 10.1 & 10.5 & 10.5 & 9.9 & 10.3 & 15.9 & 82 \\
\hline $\mathrm{T} 3$ & 10.3 & 0.8 & 2.2 & 1.0 & 2.1 & 3.0 & 10.8 & 10.4 & 9.7 & 9.3 & 10.8 & 15.6 & 86 \\
\hline \multicolumn{14}{|c|}{2019} \\
\hline T1 & 19.0 & 8.0 & 6.5 & 2.2 & 7.6 & 11.2 & 13.1 & 2.8 & 3.1 & 1.8 & 3.4 & 3.1 & 82 \\
\hline $\mathrm{T} 2$ & 19.3 & & & & 8.8 & 14.0 & 13.6 & 1.8 & 3.2 & 2.0 & 3.4 & 3.3 & 71 \\
\hline T3 & 19.4 & 4.1 & 3.3 & 2.1 & 8.5 & 13.0 & 12.9 & 2.3 & 2.9 & 1.8 & 3.3 & 3.0 & 77 \\
\hline
\end{tabular}

Monthly mean crop for three clones for three treatments and for two years are shown in Figures from 1a to 1f. No significant differences in mean monthly crops were recorded for three treatments except for the months in which tappings were not done or tapping was done at $\mathrm{d} 6$ frequency for the clone RRIC 100 for 
P Seneviratne et al.

2018 (Fig. 1a). More or less similar patterns were recorded in RRIC 121 and RRISL 203 for 2018 (Figs. 1c and 1e). However, a significantly higher annual total crop $(\mathrm{kg})$ was recorded for $\mathrm{T} 1$ when compared with T2 and T3 in RRIC 100 and in RRIC 121for 2018 (Figs. 1a and 1c). Nevertheless, the annual total crop for T1 was in par with T3 for RRISL 203 for 2018 (Fig. 1e). Interestingly, higher $\mathrm{g} / \mathrm{t} / \mathrm{t}$ values were recorded for $\mathrm{T} 2$ as compared to $\mathrm{T} 1$ and $\mathrm{T} 3$ in all three clones for 2018.

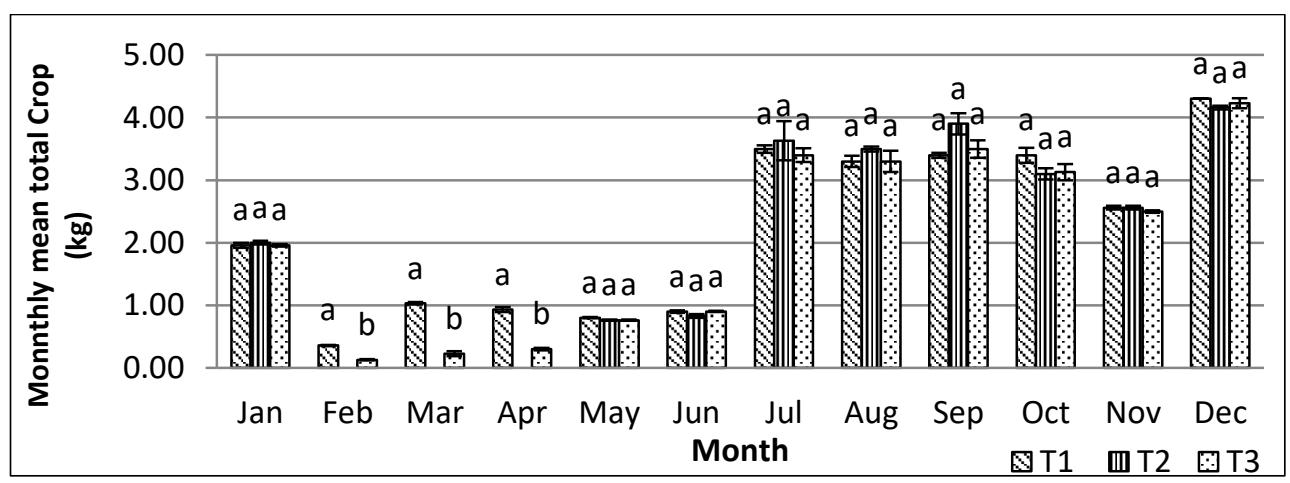

Fig. 1a. Mean monthly latex yield $(\mathrm{kg})$, for the clone RRIC 100 for three treatments, T1- continuous Tapping, T2- winter rested and T3- d6 tapping during the wintering period for 2018 .

Means followed by the same letter ( $s$ ) are not significantly different at $\mathrm{p} \leq 0.05$, according to Duncan's Multiple Range Test (DMRT). Standard error of the mean is shown on the column.

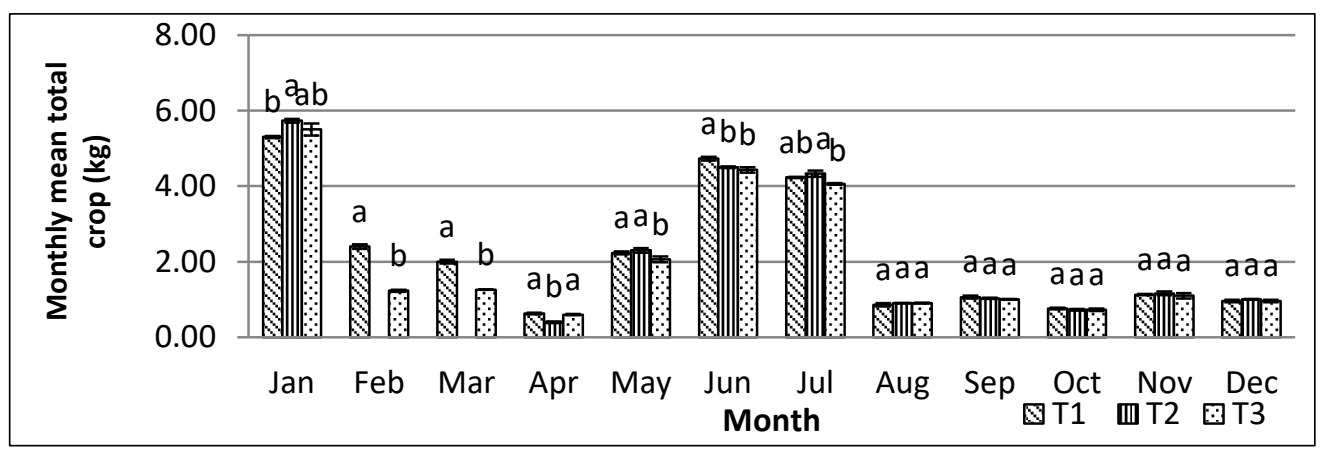

Fig. 1b. Mean monthly latex yield (kg), for the clone RRIC 100 for three treatments, T1continuous Tapping, T2- winter rested and T3- $\mathrm{d} 6$ tapping during the wintering period for 2019.

Means followed by the same letter (s) are not significantly different at $p \leq 0.05$, according to Duncan's Multiple Range Test (DMRT). Standard error of the mean is shown on the column. 
Monthly mean crop from August to December is very low with compared to the same period of 2018 , owing to loss of tapping days due to heavy rain.

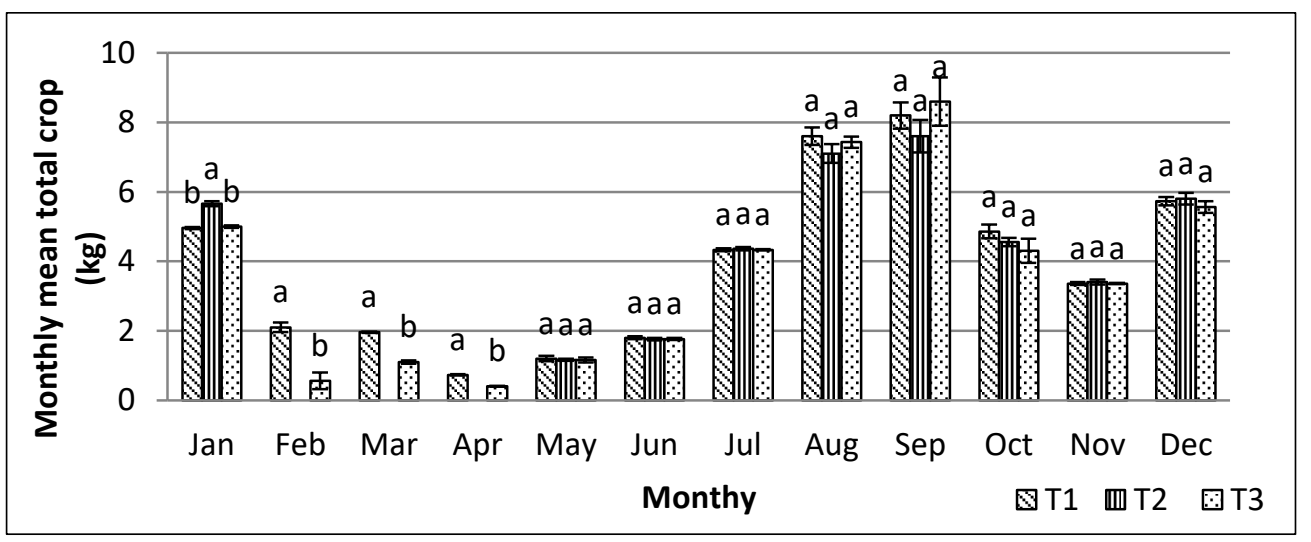

Fig. 1c. Mean monthly latex yield (kg), for the clone RRIC 121 for three treatments, T1- continuous Tapping, T2- winter rested and T3- d6 tapping during the wintering period for 2018

Means followed by the same letter ( $s$ ) are not significantly different at $\mathrm{p} \leq 0.05$, according to Duncan's Multiple Range Test (DMRT). Standard error of the mean is shown on the column.

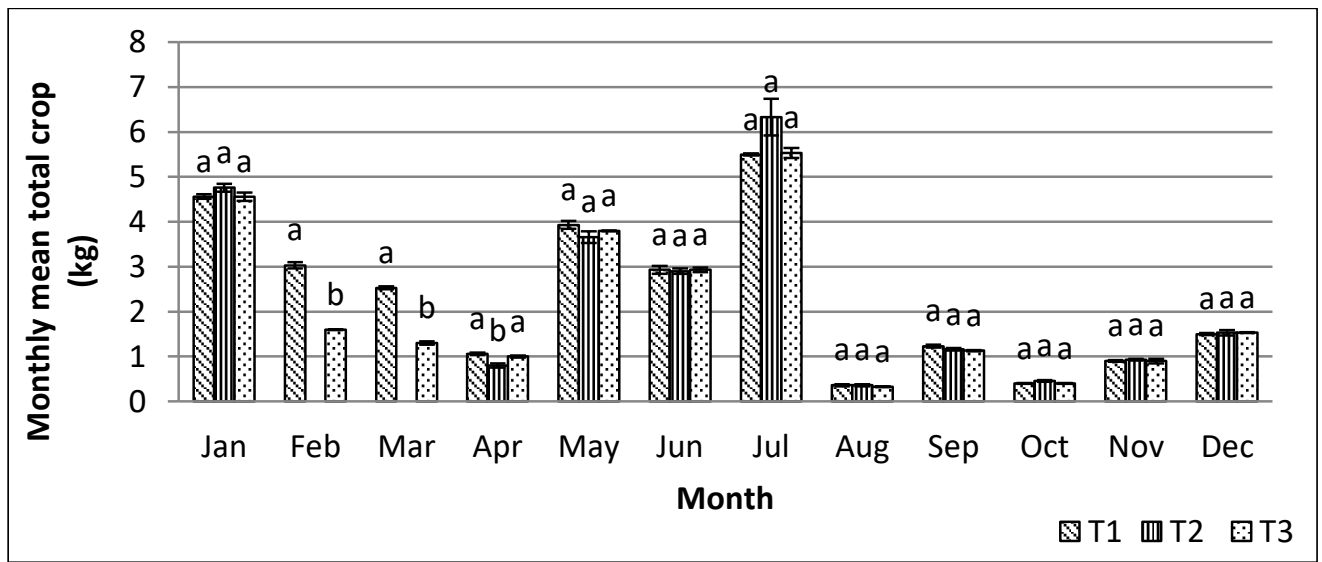

Fig. 1d. Mean monthly latex yield (kg), for the clone RRIC 121 for three treatments, T1- continuous Tapping, T2- winter rested and T3- d6 tapping during the wintering period for 2019

Means followed by the same letter ( $s$ ) are not significantly different at $\mathrm{p} \leq 0.05$, according to Duncan's Multiple Range Test (DMRT). Standard error of the mean is shown on the column. 
P Seneviratne et al.

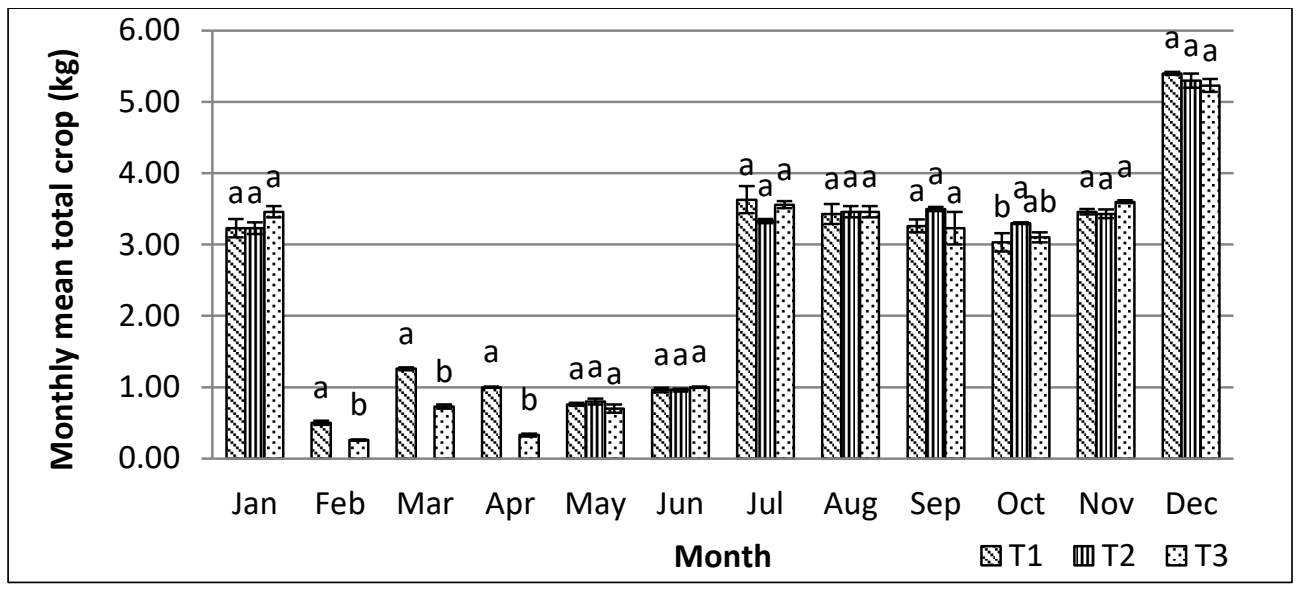

Fig. 1e. Mean monthly latex yield (kg), for the clone RRISL 203 for three treatments, T1- continuous Tapping, T2- winter rested and T3- d6 tapping during the wintering period for 2018

Means followed by the same letter ( $s$ ) are not significantly different at $p \leq 0.05$, according to Duncan's Multiple Range Test (DMRT). Standard error of the mean is shown on the column.

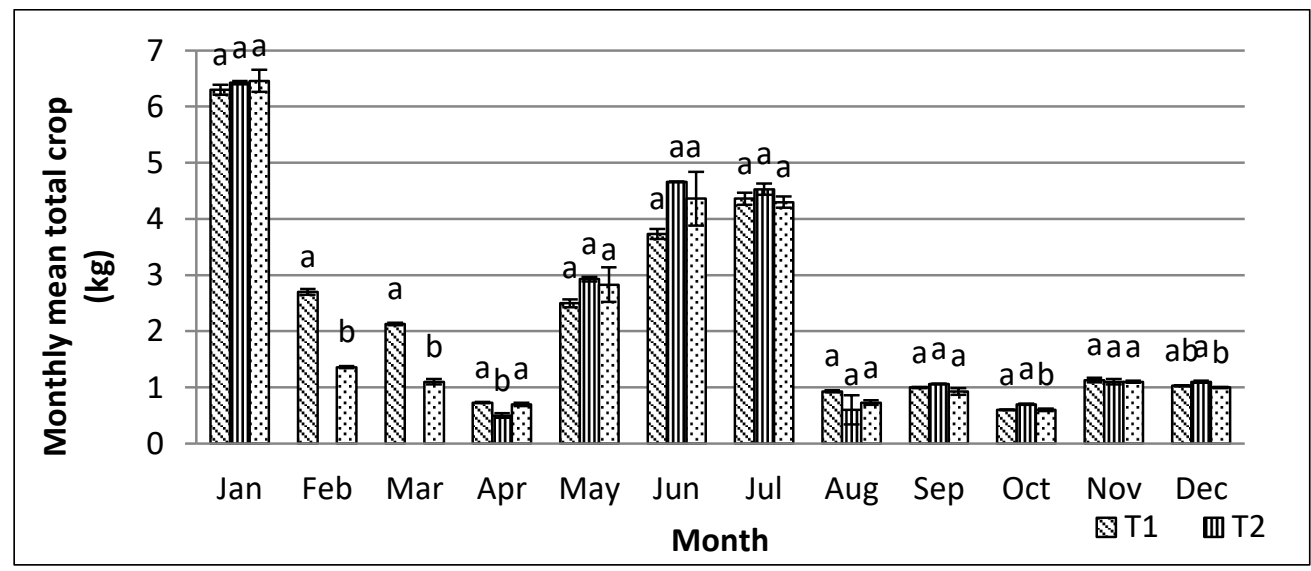

Fig. 1f. Mean monthly latex yield $(\mathrm{kg})$, for the clone RRISL 203 for three treatments, T1- continuous Tapping, T2- winter rested and T3- d6 tapping during the wintering period for 2019

Means followed by the same letter ( $s$ ) are not significantly different at $p \leq 0.05$, according to Duncan's Multiple Range Test (DMRT). Standard error of the mean is shown on the column. 
The number of trees per treatment, number of tapping days, number of tapping days as a \% of continuous tapping days, annual total crop for 30 trees (TC), annual total crop as a \% of continuous tapping treatment, average crop per tree per tapping $(\mathrm{g} / \mathrm{t} / \mathrm{t}), \mathrm{g} / \mathrm{t} / \mathrm{t}$ as a $\%$ of continuous tapping, crop per tapping day for 30 trees, \% crop increase with reference to continuous tapping, for two consecutive years 2018 and 2019 for the clones RRIC 100, RRIC 121 and RRISL 203 are given in Tables 2a,2b and $2 \mathrm{c}$. As it is clear from Table $2 \mathrm{a}$, the number of tapping days as a $\%$ of that of continuous tapping is different correlating to the length of the winter resting period. In 2018 , only $74.7 \%$ of the tapping days have been tapped but $92.9 \%$ of the crop has been achieved. Similarly, g/t/t or the crop per tapping day per 30 trees show $24.4 \%$ increase. But in year 2019, \% number of tapping days is higher than that of 2018 (77\%), due to shorter wintering period and therefore the $\%$ increase of $\mathrm{g} / \mathrm{t} / \mathrm{t}$ or the crop per tapping day per 30 trees is lower than that of year $2018(8 \%)$. The data for d6 tapping during the wintering period also behave in the same pattern for two years. However, when the number of tapping days per annum is lower, the $\mathrm{g} / \mathrm{t} / \mathrm{t}$ is higher.

Table 2a. The number of trees per treatment, number of tapping days, number of tapping days as a \% of continuous tapping days, annual total crop for 30 trees (TC), annual total crop as a \% of continuous tapping, average crop per tree per tapping $(\mathrm{g} / \mathrm{t} / \mathrm{t}), \mathrm{g} / \mathrm{t} / \mathrm{t}$ as $a \%$ of continuous tapping, crop per tapping day for 30 trees, \% crop increase with reference to continuous tapping, for two consecutive years 2018 and 2019 for the clone RRIC 100

\begin{tabular}{|c|c|c|c|c|c|c|c|c|c|}
\hline \multirow[b]{2}{*}{ 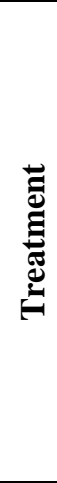 } & \multicolumn{9}{|c|}{2018} \\
\hline & 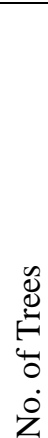 & 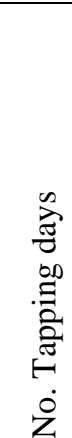 & 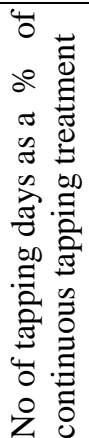 & 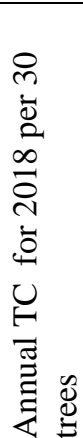 & 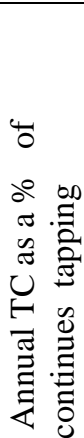 & 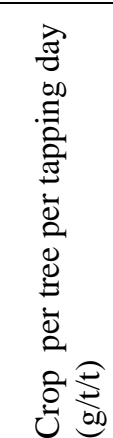 & 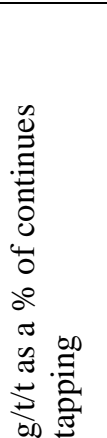 & 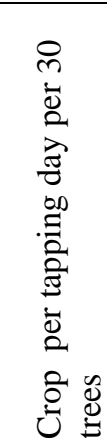 & 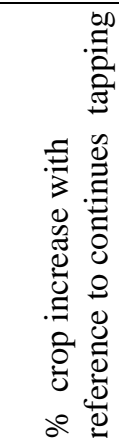 \\
\hline T1 & 30 & 91 & 100 & 79.0 & 100 & 28.94 & 100 & 0.868 & 100 \\
\hline T2 & 30 & 68 & 74.7 & 73.4 & 92.9 & 36.00 & 124.4 & 1.080 & 124.4 \\
\hline T3 & 30 & 76 & 83.5 & 72.9 & 92.2 & 31.96 & 110.5 & 0.959 & 110.5 \\
\hline & \multicolumn{9}{|c|}{2019} \\
\hline T1 & 30 & 83 & 100 & 78.8 & 100 & 31.65 & 100 & 0.95 & 100 \\
\hline T2 & 30 & 64 & 77.1 & 66.0 & 83.6 & 34.39 & 108.7 & 1.03 & 108.4 \\
\hline T3 & 30 & 74 & 89.2 & 71.6 & 90.9 & 32.27 & 102 & 0.97 & 102 \\
\hline
\end{tabular}


P Seneviratne et al.

As shown in Table $2 b$, the number of tapping days as a $\%$ of that of continuous tapping is different correlating to the length of the winter resting period for the clone RRIC 121 too. In 2018, only $76.1 \%$ of the tapping days have been tapped but $88.6 \%$ of the crop has been achieved. Similarly, $\mathrm{g} / \mathrm{t} / \mathrm{t}$ or the crop per tapping day per 30 trees show $16.4 \%$ increase. In the year 2019, \% number of tapping days is similar to that of 2018
(76\%), despite the shorter wintering period and the $\%$ increase of $\mathrm{g} / \mathrm{t} / \mathrm{t}$ or the crop per tapping day per 30 trees is lower than that of year 2018 (7.6\%). The data for d6 tapping during the wintering period also behave in the same pattern for two years. However, when the number of tapping days per annum is lower, the $\mathrm{g} / \mathrm{t} / \mathrm{t}$ is higher for the clone RRIC 121 also.

Table 2b. The number of trees per treatment, number of tapping days, number of tapping days as a \% of continuous tapping days, annual total crop for 30 trees (TC), annual total crop as a \% of continuous tapping, average crop per tree per tapping $(\mathrm{g} / \mathrm{t} / \mathrm{t}), \mathrm{g} / \mathrm{t} / \mathrm{t}$ as $a \%$ of continuous tapping, crop per tapping day for 30 trees, \% crop increase with reference to continuous tapping, for two consecutive years 2018 and 2019 for the clone RRIC 121

\begin{tabular}{|c|c|c|c|c|c|c|c|c|c|}
\hline \multirow[b]{2}{*}{ 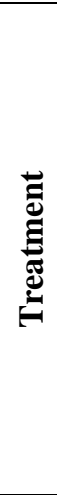 } & \multicolumn{9}{|c|}{2018} \\
\hline & 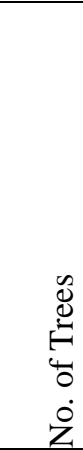 & 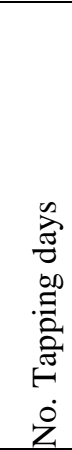 & 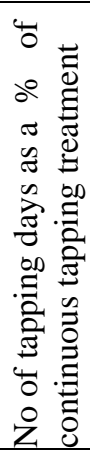 & 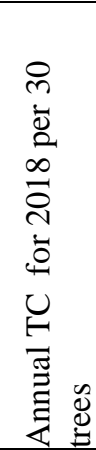 & 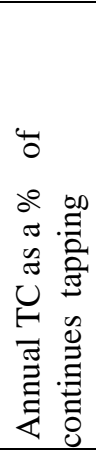 & 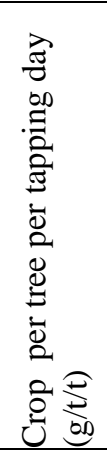 & 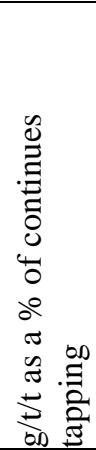 & 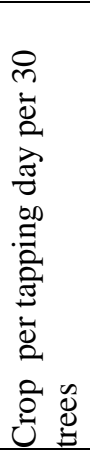 & 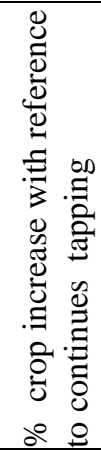 \\
\hline T1 & 30 & 88 & 100 & 140.7 & 100 & 53.28 & 100 & 1.60 & 100 \\
\hline $\mathrm{T} 2$ & 30 & 67 & 76.1 & 124.6 & 88.6 & 62.00 & 116.4 & 1.86 & 116.3 \\
\hline T3 & 30 & 77 & 87.5 & 131.1 & 93.2 & 56.76 & 106.5 & 1.70 & 106.3 \\
\hline & \multicolumn{9}{|c|}{2019} \\
\hline T1 & 30 & 75 & 100 & 84 & 100 & 37.33 & 100 & 1.12 & 100 \\
\hline $\mathrm{T} 2$ & 30 & 57 & 76 & 68.7 & 81.8 & 40.16 & 107.6 & 1.20 & 107.1 \\
\hline T3 & 30 & 66 & 88 & 75.4 & 89.8 & 38.07 & 101.2 & 1.14 & 101.8 \\
\hline
\end{tabular}


Table $2 \mathrm{c}$ shows the data for clone RRISL 203. The number of tapping days as a $\%$ of that of continuous tapping in 2018 is only $74 \%$ of the continuous tapping but $91 \%$ of the crop has been achieved. Similarly, g/t/t or the crop per tapping day per 30 trees show $23.8 \%$ increase. In the year 2019, \% number of tapping days is similar to that of $2018(78 \%)$, but due to shorter winter rest period the $\%$ increase of $\mathrm{g} / \mathrm{t} / \mathrm{t}$ or the crop per tapping day per 30 trees is lower than that of year 2018 (10.7\%). The data for d6 tapping during the wintering period also behave in the same pattern for two years. For the clone RRISL 203 too, the lower number of tapping days per annum resulted higher $\mathrm{g} / \mathrm{t} / \mathrm{t}$ though the differences are there for two years with different lengths of wintering periods.

The total crop harvested from 30 trees for three clones and for three treatments, continuous tapping (T1), winter rested (T2) and d6 tapping during the wintering period (T3) during the year 2018, are shown in Figure 2a. Significantly higher annual total crop have been harvested for the clones RRIC 100 and RRIC 121 for both years. For RRISL 203, total annual crop values are not significantly different for the three treatments.

Table 2c. The number of trees per treatment, number of tapping days, number of tapping days as a \% of continues tapping days, annual total crop for 30 trees (TC), annual total crop as a \% of continues tapping, average crop per tree per tapping $(\mathrm{g} / \mathrm{t} / \mathrm{t}), \mathrm{g} / \mathrm{t} / \mathrm{t}$ as $a \%$ of continues tapping, crop per tapping day for 30 trees, \% crop increase with reference to continues taping, for two consecutive years 2018 and 2019 for the clone RRISL 203

\begin{tabular}{|c|c|c|c|c|c|c|c|c|c|}
\hline \multirow[b]{2}{*}{ 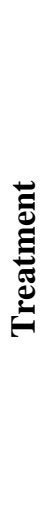 } & \multicolumn{9}{|c|}{2018} \\
\hline & 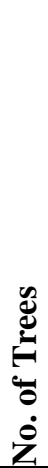 & 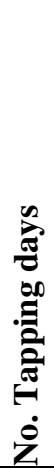 & 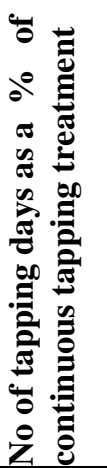 & 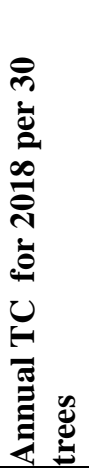 & 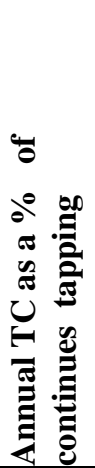 & 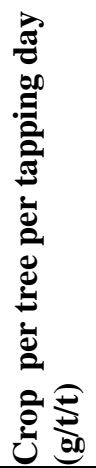 & 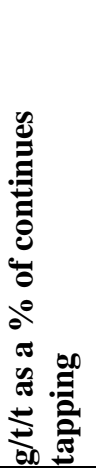 & 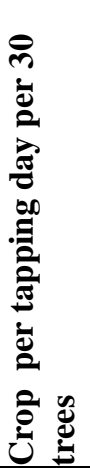 & 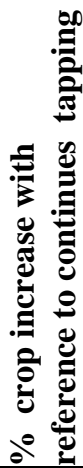 \\
\hline T1 & 30 & 87 & 100 & 90.1 & 100 & 34.51 & 100 & 1.04 & 100 \\
\hline T2 & 30 & 64 & 74 & 82.0 & 91 & 42.73 & 123.8 & 1.28 & 123.1 \\
\hline T3 & 30 & 75 & 86 & 86.0 & 95.4 & 38.21 & 110.7 & 1.15 & 110.6 \\
\hline & \multicolumn{9}{|c|}{2019} \\
\hline T1 & 30 & 82 & 100 & 81.8 & 100 & 33.25 & 100 & 1.00 & 100 \\
\hline T2 & 30 & 64 & 78 & 70.7 & 86.4 & 36.82 & 110.7 & 1.10 & 110 \\
\hline T3 & 30 & 73 & 89 & 76.7 & 93.8 & 35.00 & 105.3 & 1.05 & 105 \\
\hline
\end{tabular}

12 
P Seneviratne et al.

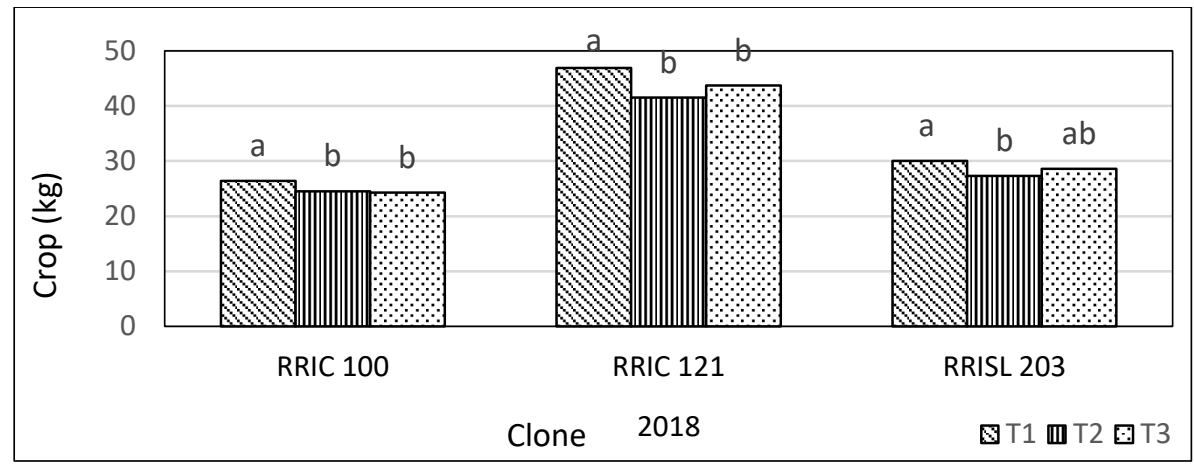

Fig. 2a. The total crop collected for three clones and for three treatments, for continuous tapping (T1), winter rested (T2) and d6 tapping during the wintering period (T3) during the year 2018. (The yields represented by the columns with the same letter are not significantly different).

The total crop collected for 30 trees for three clones and for three treatments, continuous tapping (T1), winter resting (T2) and $\mathrm{d} 6$ tapping during the wintering period (T3) during the year 2019, are shown in Figure $2 \mathrm{~b}$. The annual total crops for the three treatments are significantly different for the clones RRIC 100 and RRIC 121. Winter rested trees gave higher $\mathrm{g} / \mathrm{t} / \mathrm{t}$ values during the rest of the months but in the year 2019, the tapping days of cropping months were affected by heavy rain for all three clones the monthly mean values were very low for the year 2019. However, for the clone RRISL 203, differences were not significant between continuous tapping and $\mathrm{d} 6$ tapping during wintering (Fig. 2b).

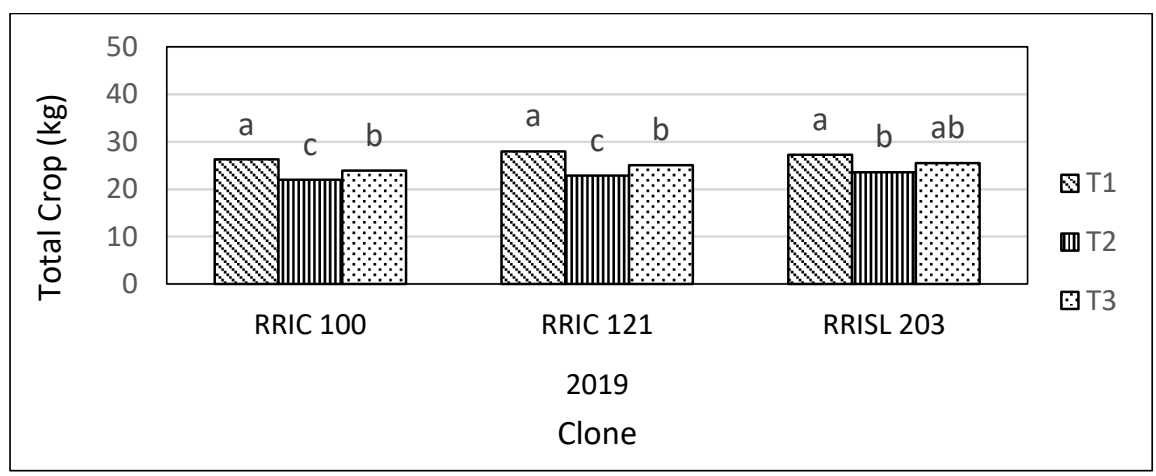

Fig. 2b. The total crop collected for three clones and for three treatments, continuous tapping (T1), winter resting (T2) and d6 tapping during the wintering period (T3) during the year 2019 (The yields represented by the columns with the same letter are not significantly different) 
The girth increment for the three treatments and for the three clones for the trial period of two years are given in Table 3. No significant differences in girth increment $(\mathrm{cm})$ values were recorded in all three treatments for all three clones.

The age of each selected clone for this trial is 25,13 and 9 years for the clones RRC 100, RRIC 121 and RRISL 203 respectively. Therefore, comparison among clones is not possible for girth increment. However, the differences among treatments are not significant for all three clones. The clone RRIC 100 has long passed its growth phase. Though not significant a higher girth increment is observed in winter rested trees of RRISL 203.

The percentage tapping panel dryness in different treatments of the three clones tested are given in Table 4. No significant differences in the incidence of tapping panel dryness (partially dry, totally dry or both together) were recorded among treatments for the clones RRIC 100 and RRISL 203. Nevertheless, significantly lower percentage of partially dry trees was recorded for winter rested trees (T2) when compared to continuous tapping (T1) in RRIC 121.

Results of the economic analysis for the treatments and three clones are given in Table 5. The profit per hectare is highest in T2 in clones RRIC 100 and RRISL 203. For the clone RRIC 121, T1 shows the highest profit. However, the benefit to cost ratio is highest in $\mathrm{T} 2$ for all three clones.

Table 3. Mean girth increment $(\mathrm{cm})$ during the study period of trees in three treatments, continuous tapping (T1), winter rested (T2) and d6 tapping during the wintering period (T3) for the period. Values in each column followed by the same letter do not differ statistically (LSD test; $p<0.05$ )

\begin{tabular}{lccc}
\hline \multirow{2}{*}{ Treatment } & \multicolumn{3}{c}{ Mean girth increment (cm) } \\
\cline { 2 - 4 } & RRIC & RRIC & RRISL \\
$\mathbf{1 0 0}$ & $\mathbf{1 2 1}$ & $\mathbf{2 0 3}$ \\
\hline T1- continues tapping with no winter rest & $1.56^{\mathrm{a}}$ & $0.46^{\mathrm{a}}$ & $0.76^{\mathrm{a}}$ \\
$\begin{array}{l}\text { T2- resting or no tapping during the wintering period } \\
\text { T3- tapping at d6 frequency during the wintering } \\
\text { period }\end{array}$ & $0.36^{\mathrm{a}}$ & $0.73^{\mathrm{a}}$ & $1.00^{\mathrm{a}}$ \\
\hline
\end{tabular}


P Seneviratne et al.

Table 4. Effect of different tapping systems during wintering period on the occurrence of tapping panel dryness percentage. Values in each column followed by the same letter do not differ statistically (LSD test; $p<0.05$ )

\begin{tabular}{|c|c|c|c|c|c|c|c|c|c|}
\hline \multirow[b]{2}{*}{ } & \multicolumn{3}{|c|}{ RRIC 100} & \multicolumn{3}{|c|}{ RRIC 121} & \multicolumn{3}{|c|}{ RRISL 203} \\
\hline & 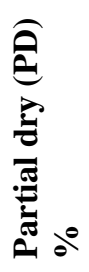 & 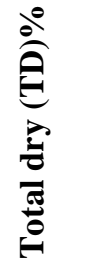 & 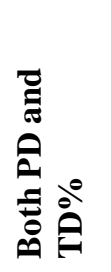 & 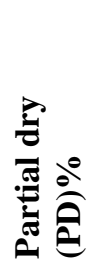 & 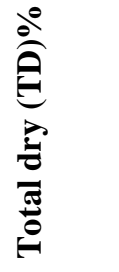 & 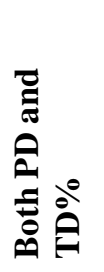 & 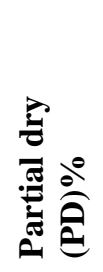 & 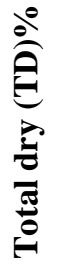 & 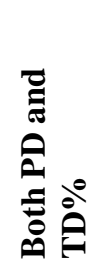 \\
\hline T1 & $23.3^{\mathrm{a}}$ & $36.7^{\mathrm{a}}$ & $60.0^{\mathrm{a}}$ & $20.0^{\mathrm{a}}$ & $33.3^{\mathrm{a}}$ & $53.3^{\mathrm{a}}$ & $30^{\mathrm{a}}$ & $20^{\mathrm{a}}$ & $50^{\mathrm{a}}$ \\
\hline $\mathrm{T} 2$ & $26.7^{\mathrm{a}}$ & $20.0^{\mathrm{a}}$ & $46.7^{\mathrm{a}}$ & $13.3^{\mathrm{ab}}$ & $33.3^{\mathrm{a}}$ & $46.7^{\mathrm{a}}$ & $20^{\mathrm{a}}$ & $30^{\mathrm{a}}$ & $50^{\mathrm{a}}$ \\
\hline T3 & $26.7^{\mathrm{a}}$ & $30.0^{\mathrm{a}}$ & $56.7^{\mathrm{a}}$ & $6.7^{\mathrm{b}}$ & $46.7^{\mathrm{a}}$ & $53.3^{\mathrm{a}}$ & $30^{\mathrm{a}}$ & $30^{\mathrm{a}}$ & $60^{\mathrm{a}}$ \\
\hline
\end{tabular}

Table 5. Economic analysis for three treatments, T1-continuous tapping, T2-winter resting and T3- $d 6$ tapping during the wintering period for three clones (BCR: benefit to cost ratio)

\begin{tabular}{|c|c|c|c|c|}
\hline Clone & & RRIC 100 & RRIC 121 & RRISL 203 \\
\hline \multirow{3}{*}{ Mean yield (kg/tree/year) } & T1 & 2.63 & 4.69 & 3 \\
\hline & $\mathbf{T 2}$ & 2.45 & 4.15 & 2.73 \\
\hline & T3 & 2.43 & 4.37 & 2.87 \\
\hline \multirow[t]{3}{*}{ Tapping days } & T1 & 107 & 107 & 107 \\
\hline & $\mathbf{T 2}$ & 80 & 80 & 80 \\
\hline & T3 & 93 & 93 & 93 \\
\hline \multicolumn{5}{|l|}{ Tapping cost per ha year } \\
\hline \multirow{3}{*}{$\begin{array}{l}\text { (labor wage*Tapping days } \\
\text { per year)/250)*500 }\end{array}$} & T1 & 214,000 & 214,000 & 214,000 \\
\hline & T2 & 160,000 & 160,000 & 160,000 \\
\hline & T3 & 186,000 & 186,000 & 186,000 \\
\hline $\begin{array}{l}\text { Labor wage (Rs.) for ethrel } \\
\text { application }\end{array}$ & T3 & 1,700 & 1,700 & 1,700 \\
\hline Total cost T3 & & 187,700 & 187,700 & 187,700 \\
\hline \multirow[t]{3}{*}{ Benefit per ha } & T1 & 395,009 & 703,310 & 450,310 \\
\hline & $\mathbf{T 2}$ & 367,245 & 623,050 & 410,230 \\
\hline & T3 & 364,370 & 655,597 & 429,850 \\
\hline \multirow{3}{*}{$\begin{array}{l}\text { Assuming other costs are } \\
\text { constant Profit per ha }\end{array}$} & T1 & 181,009 & 489,310 & 236,310 \\
\hline & $\mathbf{T 2}$ & 207,245 & 463,050 & 250,230 \\
\hline & T3 & 176,670 & 467,897 & 242,150 \\
\hline \multirow{3}{*}{$\begin{array}{l}\text { Assuming other costs are } \\
\text { constant BCR }\end{array}$} & T1 & 1.85 & 3.29 & 2.10 \\
\hline & T2 & 2.30 & 3.89 & 2.56 \\
\hline & T3 & 1.94 & 3.49 & 2.29 \\
\hline
\end{tabular}




\section{Discussion}

Pattern of wintering seems to depend mainly on geo-climatological conditions, the clone, age and the weather. The annual yield pattern of a rubber tree basically indicates the yield that can be harvested and in the present study the general pattern is shown in both years. Though it correlates with the weather to a greater extent, re-foliation and flowering seem to have a greater impact on the crop that is harvested during wintering months. Crop reduction starts with defoliation and gets to the maximum with re-foliation and flowering, indicating the tree's priorities. The present study further confirms the findings of previous studies on the direct relationship of the crop and the weather for re-foliation when the pattern of defoliation of 2018 and 2019 are examined. Once the defoliation completes re-foliation commences irrespective of the weather as shown by the data of the present study.

The monthly crop of the present study indicates a clear reduction during the wintering period. In 2018, significantly low yields are observed for five months, from February to June for all three clones and for all three treatments, due to longer wintering period. In 2019, when the wintering period was shorter, i.e., February to March, significantly low yields were observed only from February to April. This confirms the impact of wintering on the yield.

In Sri Lanka, although winter resting had been practiced by both small holders and plantation companies until 1970's, the practice has gradually disappeared under the present scenario. The common belief in early time was that tapping rest could give some additional benefit to the rubber tree, especially to minimize the effect of stress imposed on tapping during the wintering period and thereby to minimize tapping panel dryness condition. In the present study, although tapping rest induced higher yield per tree per tapping $(\mathrm{g} / \mathrm{t} / \mathrm{t})$ in all three clones over the two year period, annual total crop obtained from trees of all three clones rested during the wintering period was significantly low as compared to crop obtained from trees with no winter rest for both 2018 and 2019. Nevertheless, no significant difference was recorded for total annual crop obtained from trees rested during the wintering period as compared to those tapped at d6 frequency in RRISL 203.

For other two clones, RRIC 100 and RRIC 121, even d6 tapping frequency did not contribute to increase the annual total crop as compared to normal $\mathrm{d} 3$ frequency with no winter rest.

The effect of winter rest on the yield had been studied by the scientists at RRISL using clones PB 86 and Nab 12 as far back as in 1964, in a field which was replanted in 1952 and opened for tapping in 1958, after six years (Annual Review, 1972). Harvesting system had been $\mathrm{S} / 2 \mathrm{~d} 2$ with and without stimulation at six month intervals during the initial years but later only with or without winter rest had been looked at. Average girth and yield recorded at the end of nine years are reported in Annual Review for 1972 and it had been concluded that the yield differences measured as $\mathrm{g} / \mathrm{t} / \mathrm{t}$ for both clones for winter rested and continuously tapped trees were not significant. These 
P Seneviratne et al.

findings must have compelled the RRISL to declare that winter resting has no effect on the total annual crop.

Chantuma, et al. (2017) have conducted a trial with the clone RRBM 600 to see the effect of winter resting on the yield. As explained by them the winter period seems very long in Thailand, especially in Chachoengsao, from January to May and resting 4-5 months seems too long to get a good income. Also, they report of poor adoption of correct $\mathrm{d} 2$ tapping system. Accordingly, they have tested on the effectiveness of different winter resting periods during this long wintering period, to recommend the most effective period. They also have reported that the winter resting has resulted in higher $\mathrm{g} / \mathrm{t} / \mathrm{t} /$ during the rest of the year though the difference is not significant. They also have reported that resting during the latter two months i.e. during the re-foliation period when the tree needs more storage food for its own internal functions, the beneficial effects are more.

In the present study, the duration of the wintering period for the two years are different and the closest reason for the shorter wintering period observed in 2019 was the severe drought that prevailed during the first few months of the year. As far as yield reduction is concerned, a marked yield reduction was observed during defoliation period which is more than during re-foliation. According to Sethuraj (1977), the extent to which clones suffer from yield depression during wintering period also depends on the clone. Some clones tend to shed and replace part of their foliage in a simultaneous manner over a long period of time, thus they do not show obvious signs of wintering where some clones become leafless for a period of time. Some of the clones fall in between these two extremes. Behavior on the yield depression is also dependent on characters of the clone. Latex metabolism is mainly regulated by the availability of sugars in the laticifers, which depends on the carbohydrate loading to the laticiferous tissues which is used at cell level (Tupy, 1998). Sucrose produced by photosynthesis in leaves are subjected to catabolism process and release acetate molecules initiate isoprene chains and provide energy that required for the biosynthesis of latex within latex vessels. It has been evident that there is a positive and highly significant correlation between sugar concentration and production of latex which accounts for the variability in yield of latex (Jacob et al., 1985). Flowering and fruit formation utilize large amounts of carbohydrate reserves which leads to low yielding phase. Therefore, the yield obtained during the wintering period is said to be comparatively low when compared to that of other months due to the low sucrose content. Nutrient drain has become a significant factor with tapping and taking out of latex during wintering. However, some of the studies have found that there is no significant damage to the physiological processes of the plants, even though they are tapped without winter resting ( $\mathrm{Ng}$ et al., 1969). As reported by them, the reduction of the number of tappings due to the resting period was compensated by the higher yield in $\mathrm{g} / \mathrm{t} / \mathrm{t}$ during the producing 
months. The longer the tapping rests during wintering season, the higher the $\mathrm{g} / \mathrm{t} / \mathrm{t}$ was. This observation was true for the yield data for 2018 and 2019 where the length of the wintering period was different. Experiments of Menattoor et al., (1991) demonstrated that the girth increment is minimum during winter months. There is a threat for occurrence of incidences like tapping panel dryness of trees if they are tapped intensively without giving any winter rest.

Five major climatic zones have been identified in India as i). tropical rain, ii). tropical wet and dry, iii). sub tropical wet iv). arid and v). desert (Priyardarshan, 2011). First three regions are identified as suitable regions for the cultivation of rubber. Rubber plantations in north-east region (eg. Tripura) experience wintering during December to January and re-flushing commences by February. Rubber cultivated in non-traditional areas of India experience a complete defoliation during the period of February to March and it is evident that Oidium like leaf diseases occurring during refoliation period (Priyadarshan, 2011). As suggested by Priyadarshan et al. (1998); latex yield becomes poor in this period due to several reasons namely, low temperature and utilization of carbohydrate reserves for re-foliation, flowering and fruit set during the months of February to April. Non-traditional areas record lowest yield during the period of January to May. Normally trees are given about four weeks rest if the soil is very dry and yield is uneconomic during re-foliation and flowering of rubber trees in India (Rubber Research Institute of India, 2002). Rubber growing areas in Brazil such as Sao Paulo, experiencing defoliation, re-flushing and seed fall once a year (Ortolani et al., 1998) and the trees are exploited throughout the year.

A study was undertaken in India, to group rubber (Hevea brasiliensis) clones based on their wintering behavior in Tripura (one of the rubber growing areas of North East India) with the objective of analyzing performance of wintering pattern in different clones. Fifteen clones from a clone evaluation trial were scored for the wintering pattern at weekly intervals for six weeks from December to February during 1988-89, 1989-90 and 1991-92 period. Wintering pattern of clones was uniform for all the years under the study. However, three distinct clusters of i) early, ii) intermediate and iii) late wintering clones were obtained viz., (i) RRII 105 and RRIC 105, (ii) RRIM 600, PB 86, GT 1, RRIC 52 and PB 235 and (iii) RRII118, RRIM 605, Gil, Harbell, RRII 5, PB 5/51 and RRIM 703. RRII 203 was found to fall in between the second and the third clusters (Vinod et al., 1996).

One of the main objectives of the present study was to see the impact of winter resting on the incidence of brown bast. As we expected a reduction in brown bast condition in trees rested during the wintering season as compared to those tapped at normal frequency (d3) or d6 frequency during the wintering, was observed for all three clones RRIC 100 and RRIC 121, but not significant. One of the possible reasons for this could be the effect of tapping employed before imposing the treatments. Trees of RRIC 100 had been tapped for 20 years, RRIC 
P Seneviratne et al.

121 for 8 years and RRISL 203 for 4 years before being subjected to present treatments during the wintering period. If incorrect tapping policies such as excessive tapping and over stimulation had been practiced, the negative effect of them could not be fully ruled out even under best tapping conditions also all three clearings had brown bast affected trees when the trial was initiated and they were excluded from selecting. Further, brown bast is a result of a long term exposure to over exploitation and two seasons of rest is not sufficient to show any effect. Furthermore, another factor contributing to mask the differences among treatments for brown bast may be that the entire Kuruwita estate has been rain guarded and tapped at $\mathrm{d} 3$ frequency with stimulation for many years. The average dry tree percentage in entire substation is very high, about $30 \%$. As it is seen in Table 4, partial dry tree percentage is also high in all three clones. Dry trees were determined when tapping is being done and there can be some trees which are nearing to dry but not showing symptoms. Therefore, effect of winter resting on incidence of dry trees should have been tested with new trees to see the difference among treatments.

The tapping panel dryness is an accumulation of stress within which exhibits after exposed to the factors contributing for many consecutive years. Therefore, future research, more physiological parameters should be included and the maintenance of the clearings to recommended standards right from the beginning is also important to get a clear understanding on physiological behavior of wintering. Effect of winter tapping seems to be prevailed throughout the year and thus throughout life cycle of rubber tree. It is important to analyze leaf samples for nutrients and growth parameters such as girth, bark thickness, growth of root systems etc. Apart from the expected effect on tapping panel dryness, incidences of other diseases also should be taken in to consideration.

The data obtained in the present study too show the differences in the $\mathrm{g} / \mathrm{t} / \mathrm{t}$ between winter rested and continuously tapped trees. But the economic analysis show a gain by resting during the wintering period. As evident by the crop figures, the rate of reduction of the crop vary among the clones and the year in the present study. The effect of winter resting on the trees becoming dry is a long term process and if continued may expect some reduction in TPD. Saving on the bark or in other words extending the tappable period is a beneficial result of winter resting. The cost of tapping is generally two thirds of the cost of production and therefore, tapping during the wintering months should be very uneconomical. Though the wintering period in Sri Lanka is not as long as in Thailand, the resting period may be reduced, more towards the re-foliation period through further trials. Martin (1969) recommends winter resting of young rubber fields where trees girth better during winter months if rested. He further states resting during the latter part of the wintering period as more effective. In conclusion, resting during the wintering, flowering and flushing period generally from February to March or 
April, length depending on the weather prevailing, will lead to reduction in total crop for a given year irrespective of clones. Resting during the wintering period increases the $\mathrm{g} / \mathrm{t} / \mathrm{t}$ for the rest of the months. Also, as confirmed by the economic analysis, winter resting is beneficial for the grower and for the tree in many ways. Although winter rest has not minimized brown bast or tapping panel dryness significantly, during the present study period of two years, lower values are reported for RRIC 100 and RRIC 121. Therefore, all recommended clones should be tested for the effect of winter resting and also for different periods, i.e. at the beginning, towards refoliation etc. for many consecutive years. New fields should be selected and also different harvesting systems need to be included in these trials.

However, based on the results of the present study, winter resting can be recommended as advantageous.

\section{Acknowledgements}

The authors wish to acknowledge the generous assistance of Dr WasanaWijesuriya, Biometrician and Ms. P.G.N. Ishani, Agricultural Economist for the statistical analysis and economic analysis respectively.

\section{References}

Annual Review (1972). Review of the Plant Science Department (pp. 11-38). Rubber Research Institute of Ceylon. Dartonfiled, Agalawatta.

Chantuma, P, Lacote, R, Sonnarth, S and Gohet, E (2017). Effect of different tapping periods during wintering and summer months on dry rubber yield of
Hevea brasiliensis in Thailand. Journal of Rubber Research 20 (4), 261-272.

Chen, S-C, Peng, S-Q, Huang G-X, Wu, K, $\mathrm{Fu}, \mathrm{X}$ and Chen, Z (2002). Association of decreased expression of a Myb transcription factor with the TPD (tapping panel dryness) syndrome in Hevea brasiliensis. Plant Molecular Biology 51(2), 51-58.

George, P J, Premakumari, D, Markose, V C and Panikkar, A O N (1980). The rubber tree (Hevea brasiliensis Muell. Arg.) In: Handbook of Natural Rubber Production in India pp. 25-31, (Ed. P.N. Radhakrishna Pillay), Rubber Research Institute of India, Kottayam, India.

Jacob, J L, Eschbch, J M, Prevot, J C, Roussel, D, Leerate, R, Chrestin, $\mathrm{H}$ and d'Anzua, J (1985). Physiological basis for latex diagnosis of the functioning of the laticiferous system in rubber trees. Proceedings International Rubber Conference 1985 (p.43). Rubber Research Institute of Malaysia, Kuala Lampur.

Li, D-J, Deng, Z, Chen, C-L, Xia, Z-H, Wu, $\mathrm{M}$ and He, $\mathrm{P}$ (2010). Identification and characterization of genes associated with tapping panel dryness from Hevea brasiliensis latex using suppression subtractive hybridization. BMC Plant Biology 10, 140.

Liyanage, A de S (1976). Influence of some factors on the pattern of wintering and on the incidence of Oidium leaf fall in clone PB 86. Journal of Rubber Research Institute of Sri Lanka 53, pp.31-38.

Martin, R (1969). Effect of tapping rest at different seasons. Journal of Rubber Research Institute of Malaya 21(3), 353359.

Meenattoor, J R, Vinod, K K, Krishnakumar, A K, Potty, S N and Sethuraj, M R (1991). Clone $\times$ environmental interaction during early growth phase of Hevea brasiliensis: 1. Clonal stability on growth. Indian 
P Seneviratne et al.

Journal of Natural Rubber Research 4(1), 51-54.

Meenattoor, R J, Krishnakumar, A K, Sinha, R R and Potty, S N (1989). Flowering pattern of Hevea clones in Tripura. Indian Journal of Natural Rubber Research 2(2), 139-142.

Nayanakantha, N M C and Seneviratne, P (2008). Wintering and flowering patterns of Hevea clones in Wet and Intermediate Zones of Sri Lanka. In: Proceedings of Plantation Crop Research 2008, 132141.

Ng, E K, Abraham, P D, P'ng, T C and Lee, C K (1969). Exploitation of modern Hevea clones. Journal of Rubber Research Institute of Malaysia 21, 292.

Ortolani, A, Sentelhas, P C, Camargo, M B P, Pezzopane, J E M and Goncalves, P de S (1998). Agro-meteorological model for seasonal rubber tree yield. Indian Journal of Natural Rubber Research 11, 8-14.

Priyadarshan, P M (2011). Biology of Hevea rubber.CAB International, Oxford shire, United Kingdom. Pp.17-164.

Priyadarshan, P M, Sowmyalth, M K S, Sasikumar, S, Vanghese, Y A and Dey, S K (1998). Relative performance of six Hevea brasiliensis clones during two yielding regimes in Tripura. Indian
Journal of Natural Rubber Research 11, 67-72.

Rubber Research Institute of India (2002). Rubber cultivation. Rubber Board. Available: Http:// rubberboard.org.in/ rubbercultivation.asp (2016.06.16).

Sethuraj, M R (1977). Studies on the physiological factors influencing yield in rubber. $\mathrm{PhD}$ Thesis, Banaras Hindu University, Varanasi, India.

Tupy, J (1988). Ribosomal polyadenylated content of rubber tree latex: Association with sucrose level and rubber latex $\mathrm{pH}$. Plant Science 55, 137-144.

Vinod, K K, Meenattoor, J R, Pothen, J, Krishnakumar, A K and Sethuraj, M R (1996). Performance analysis for wintering pattern in Hevea brasiliensis clones. Indian Journal of Natural Rubber Research 9 (1), 44-47.

Wimalarathne, S D and Pathiratna, L S S (1974). Observation on 'wintering' in Hevea. Bulletin of the Rubber Research Institute of Sri Lanka 9 (1), 5-9.

Address for correspondence: Dr (Mrs) $\mathrm{P}$ Seneviratne, Deputy Director Research Biology, Rubber Research Institute of Sri Lanka, Dartonfield, Agalawatta, Sri Lanka. e-mail:ddrbiorrisl@gmail.com 